adoption of the syllabus by all authorities is of greater importance at the present moment than the details of the contents.

It may be predicted, therefore, that the recommendations of the report so far as they are concerned with the pre-medical studies and the age for commencement of medical studies proper will receive the enthusiastic support of teachers in public and other secondary schools. If the recommendations are carried into effect, the complaints of undue specialisation and too low a standard of general education will largely disappear, and the medical students produced by the schools may be better fitted to "acquire that kind of culture which survives the forgetting of facts".

W. J. R. D.

\title{
Geology as a School Subject
}

$A^{\mathrm{T}}$ the Norwich meeting of the British Association, a discussion was held in Section C (Geology) on "Geology in Schools". It was certainly appropriate that this subject should be discussed during the year in which Prof. W. W. Watts is president of the Association, for during a period of more than thirty years he has repeatedly pressed the claims of geology as a school science subject, and his presidential address to Section C in 1903 dealt comprehensively with the functions of geology in education. For various reasons, little progress has been made with the introduction of the subject into schools, although in the meantime there has been a great extension of science teaching.

The Norwich discussion may be summarised the more easily since it revealed a remarkable unanimity of opinion, practically all who spoke emphasising their agreement with the previous speakers. It was keenly felt that geology does not occupy the place to which it is entitled in the educational system, in schools, universities or in the wider field of adult education. Dr. A. K. Wells showed that the number taking geology in the University of London General Schools Examinations has fallen almost to zero. On the other hand, many speakers emphasised the fact that geology proves one of the most attractive sciences when once a student is introduced to it. As Prof. Watts said: "there are many types of mind to whom this science appeals as no other one does": it gives a new interest which frequently lasts beyond school days, and which gives meaning to every piece of country visited, an important fact in these days of wider travel. Prof. P. G. H. Boswell stressed the value of geology as a cultural subject, and quoted Mr. Ramsay MacDonald's statement that "if any one of the sciences were selected as the key to all the other sciences-as that which in its subject-matter and its history, the history of its evolution, enforces the true scientific methodgeology might be selected as that science".

In the course of the discussion, many advantages of geology as a school subject were touched upon.
Among these the most important appears to be that geology is perhaps the very best training ground in the collection and co-ordination of observed facts. It was also emphasised that the equipment necessary for teaching (more abundant and more easily obtained now than at any time) is probably less expensive than in any other science. Many rural schools are situated in areas which can be described as natural laboratories, and it is preposterous that scholars do not learn something of the meaning of these surroundings. On the other hand, Dr. H. D. Thomas referred to the valuable work in geology done in a London school, so that the teaching of the subject by no means needs to be confined to rural areas. Prof. A. Hubert Cox spoke of the excellent work now being done in some Welsh schools, and Mr. A. N. Thomas gave an account of the courses provided at Caerphilly.

It was also pointed out that in several sciences taught in schools the teaching has become increasingly dogmatic: even the experiments performed are "carefully designed to eliminate all confusing and collateral elements". At least some teachers of chemistry and physics consider that the elementary parts of those subjects must be mastered as quickly as possible, and that it is impossible for a student until he approaches the standard of an honours graduate to begin to assess for himself the real value of experimental evidence or to develop his originality and critical ability. There is a real danger that a pupil finishing his science training in school may have acquired a vast body of scientific information, but may have had little chance of developing that scientific outlook which is likely to make him a more valuable member of most communities. In geology, on the other hand, it is still possible for a beginner to feel the excitement of making new discoveries; a fossil or a dip observation in a temporary section may be vitally important. The co-ordination of such observed facts, and the examination of alternative hypotheses concerning which the 
teacher is prepared to admit his own uncertainty, are all part of the training of the most elementary student.

Other changes in school organisation in late years have, however, affected the question of what sciences ought to be taught. In the first place, the great extension of the senior classes in elementary schools has opened up a new field. The teachers in these schools, to a large extent freed from the tyranny of examinations, have opportunities of devising courses in science on more original lines ; often limited by lack of laboratories and apparatus, the teaching of science must become even more dogmatic unless it is extended to include subjects such as geology in which the provision of simple equipment offers no difficulties : moreover, as Prof. Watts emphasised, it is possible to do a considerable amount of geology without any special knowledge of other sciences.

In the secondary schools the position presents greater difficulties. The teaching is frequently dominated by examinations; the needs of the small proportion of pupils who may eventually proceed to the university to a large extent determine the subjects chosen; the curriculum is already crowded, at least so far as the School Certificate stage. But many educationists feel that all is not well with science teaching at this stage and that the tendency to early specialisation imposes serious limitations on the teacher. Recently the panel of investigators appointed by the Secondary Schools Examinations Council concluded that "at present the practice is to confine Science work too narrowly and this practice is encouraged by our examination system". They believe that "there is a general body of knowledge ... . which ought to be known both by the ordinary citizen and by those who may ultimately specialise" in some narrower field, and recommend the institution of a course in elementary or general science to be made obligatory for practically all candidates desiring a pass in science at the School Certificate examination. The scheme now proposed involves some physics, chemistry and biology ; in the course of the discussion at Norwich the view was very strongly expressed that some geology should be included in this general course.

The difficulty, already widely discussed, of making a homogeneous subject out of this new group would not necessarily be made greater by the inclusion of geology. For geology occupies a central position among the sciences, having close contact with all, and it was suggested that the geology would help to synthesise the scheme. In many cases it would form a suitable basis for the study both of science and of the external world. In this connexion, Prof. H. H. Swinnerton referred to a Nottingham school where a course in local geology and biology forms the starting point of all science work.

Several speakers felt that the introduction of geology as a separate subject after the School Certificate stage, for Higher School Certificate pupils, was highly desirable. The higher work done in school represents for some pupils the last stage of organised study, for others it forms the basis of subsequent university work; but for both these groups the inclusion of additional science subjects in the curriculum of most schools is greatly to be desired. Usually not more than three subjects are studied to this higher stage, and often in smaller schools no more than that number of science subjects is available: the pupil's choice at best is limited, and he may be excluded from any course in 'science' because, for example, of a distaste for physics or mathematics. For those who are not likely to proceed to university work in science, the advantages of a scheme which includes geology will be apparent from the remarks already summarised.

It was pointed out that the case of the student who intends to go to a university to read science calls for still more consideration, for the position has been greatly altered by the growth of the Higher Certificate courses. In most universities satisfactory school work at the higher stage gives exemption from first year university courses. But whereas in the past a matriculated student going to the university had to choose (usually) four science subjects from a list of seven or eight, which mostly involved taking up at least one subject which he had not studied at school, the present student has already made his narrower choice at school. There is a probability, therefore, that students who may have marked abilities in sciences not taught at school may never discover that bent, and may indeed be deterred from reading science at all. The effect of these conditions on the geology departments at the universities was commented on, although obviously this in itself is no strong reason for instituting geology courses in schools.

The relations of geology to the geography taught in schools were also discussed by several speakers. Prof. A. Gilligan emphasised the importance of geological work as a basis for school geography, and Dr. M. E. Tomlinson gave her experience, as a geography teacher, of the great interest taken by both boys and girls in the geology which she had, of necessity, introduced into her geography lessons.

The president of the Section (Prof. G. Hickling) mentioned that a sectional committee had been appointed to consider questions affecting the teaching of geology in schools. A. E.T. 